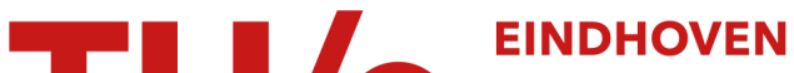 \\ UNIVERSITY OF \\ TECHNOLOGY
}

\section{Local formation of a Heusler structure in CoFe-Al alloys}

Citation for published version (APA):

Wurmehl, S., Jacobs, P. J., Kohlhepp, J. T., Swagten, H. J. M., Koopmans, B., Maat, S., Carey, M. J., \& Childress, J. R. (2011). Local formation of a Heusler structure in CoFe-Al alloys. Applied Physics Letters, 98(1), 012506-1/3. [012506]. https://doi.org/10.1063/1.3517490

DOI:

$10.1063 / 1.3517490$

Document status and date:

Published: 01/01/2011

\section{Document Version:}

Publisher's PDF, also known as Version of Record (includes final page, issue and volume numbers)

\section{Please check the document version of this publication:}

- A submitted manuscript is the version of the article upon submission and before peer-review. There can be important differences between the submitted version and the official published version of record. People interested in the research are advised to contact the author for the final version of the publication, or visit the $\mathrm{DOI}$ to the publisher's website.

- The final author version and the galley proof are versions of the publication after peer review.

- The final published version features the final layout of the paper including the volume, issue and page numbers.

Link to publication

\section{General rights}

Copyright and moral rights for the publications made accessible in the public portal are retained by the authors and/or other copyright owners and it is a condition of accessing publications that users recognise and abide by the legal requirements associated with these rights.

- Users may download and print one copy of any publication from the public portal for the purpose of private study or research.

- You may not further distribute the material or use it for any profit-making activity or commercial gain

- You may freely distribute the URL identifying the publication in the public portal.

If the publication is distributed under the terms of Article 25fa of the Dutch Copyright Act, indicated by the "Taverne" license above, please follow below link for the End User Agreement:

www.tue.nl/taverne

Take down policy

If you believe that this document breaches copyright please contact us at:

openaccess@tue.nl

providing details and we will investigate your claim. 


\title{
Local formation of a Heusler structure in CoFe-Al alloys
}

\author{
S. Wurmehl, ${ }^{1, a)}$ P. J. Jacobs, ${ }^{2}$ J. T. Kohlhepp, ${ }^{2}$ H. J. M. Swagten, ${ }^{2}$ B. Koopmans, ${ }^{2}$ S. Maat ${ }^{3}$ \\ M. J. Carey, ${ }^{3}$ and J. R. Childress ${ }^{3}$ \\ ${ }^{1}$ Institute for Solid State Research, IFW Dresden, P.O. Box 270116, D-01171 Dresden, Germany \\ ${ }^{2}$ Eindhoven University of Technology, 5600 MB Eindhoven, The Netherlands \\ ${ }^{3}$ San Jose Research Center, Hitachi GST, 3403 Yerba Buena Road, San Jose, California 95135, USA
}

(Received 19 August 2010; accepted 28 October 2010; published online 4 January 2011)

\begin{abstract}
We systematically study the changes in the local atomic environments of $\mathrm{Co}$ in $\mathrm{CoFe}-\mathrm{Al}$ alloys as a function of $\mathrm{Al}$ content by means of nuclear magnetic resonance. We find that a $\mathrm{Co}_{2} \mathrm{FeAl}$ Heusler type structure is formed on a local scale. The observed formation of a highly spin-polarized Heusler compound may explain the improved magnetotransport properties in $\mathrm{CoFe}-\mathrm{Al}$ based current-perpendicular-to-the-plane spin-valves. (C) 2011 American Institute of Physics.

[doi:10.1063/1.3517490]
\end{abstract}

Current perpendicular-to-the-plane giant magnetoresistive (CPP-GMR) read heads are being considered as a follow-up technology for tunnel magnetoresistive read heads. ${ }^{1,2}$ A crucial issue for the success of such devices is to further enhance the GMR ratio particularly at room temperature. In this context, highly spin-polarized materials are promising candidates to increase the bulk spin-scattering asymmetry and to enhance the (CPP-)GMR. Band structure calculations have shown that various Heusler compounds exhibit $100 \%$ spin polarization at the Fermi level. ${ }^{3}$ Thus, the implementation of Heusler compounds in CPP-GMR spinvalves seems desirable. ${ }^{4-6}$ However, annealing temperatures higher than $300{ }^{\circ} \mathrm{C}$ which are usually necessary to obtain the highly ordered $L 2_{1}$ phase are incompatible with reliable device fabrication. An enhancement of the CPP-GMR was also observed by addition of $\mathrm{Al}$ to a $\mathrm{CoFe}$ alloy, even with a low annealing temperature $\mathrm{T} \sim 250{ }^{\circ} \mathrm{C} .{ }^{1,2}$ The composition with highest MR was found to be $\left(\mathrm{Co}_{50} \mathrm{Fe}_{50}\right)_{75} \mathrm{Al}_{25}$. ${ }^{2}$ The authors concluded that the addition of $\mathrm{Al}$ to $\mathrm{CoFe}$ increases the resistivity of the magnetic layers while maintaining a high degree of bulk spin-dependent scattering that leads to an enhanced GMR signal. In order to further optimize $\mathrm{CoFe}-\mathrm{Al}$ spin-valves, it is important to understand the impact of the Al alloying on the local and electronic structure. In this paper, we report on a study of the local chemical structure of $(\mathrm{CoFe})_{1-x} \mathrm{Al}_{x}$ films used for CPP-GMR spin-valves by means of spin echo nuclear magnetic resonance (NMR). The sensitivity of NMR even to small changes in the local (magnetic and electronic) environment makes NMR an ideal method to determine the local modifications upon addition of $\mathrm{Al}^{7,8}$ Here, we demonstrate the local formation of a Heusler-like structure by addition of $\mathrm{Al}$ to a $\mathrm{CoFe}$ alloy. The observed local ordering is apparently correlated with the observed enhancement of the GMR effect.

See supplementary material and Refs. 2,7,8 for experimental details. ${ }^{9}$

In order to separate the contribution of $\mathrm{Al}$ on the local structure from the pure $\mathrm{CoFe}$ contributions, we also studied nominal CoFe samples as a reference. The composition of the CoFe sample was determined by XRF analysis to be $51.6 \pm 0.5$ at. $\% \mathrm{Co}$ and $48.4 \pm 0.5$ at. \% Fe. In the case of a perfectly ordered structure for $\mathrm{Co}_{50} \mathrm{Fe}_{50}$, the formation of a

${ }^{a)}$ Electronic mail: s.wurmehl@ifw-dresden.de.
$B 2$ type lattice ( $\mathrm{CsCl}$ type) is expected with exactly eight $\mathrm{Fe}$ next neighbors for each ${ }^{59} \mathrm{Co}$ nucleus. However, previous NMR measurements of $\mathrm{Co}_{50} \mathrm{Fe}_{50}$ alloys indicated the formation of a body centered cubic (bcc) lattice ${ }^{10}$ with a random distribution of $\mathrm{Co}$ and $\mathrm{Fe}$ atoms. In such a randomly ordered alloy, the first coordination sphere of the NMR active ${ }^{59} \mathrm{Co}$ nuclei consists of eight atoms. The random intermixing of $\mathrm{Co}$ and $\mathrm{Fe}$ creates nine possible configurations $(8 \mathrm{Co}+0 \mathrm{Fe}, 7 \mathrm{Co}$ $+1 \mathrm{Fe}, \ldots$, or $0 \mathrm{Co}+8 \mathrm{Fe}$ ) for the first nearest neighbor shell of a ${ }^{59} \mathrm{Co}$ nucleus. The random distribution of $\mathrm{Co}$ and $\mathrm{Fe}$ is mathematically described by a binomial distribution. The probability $P(n, x)$ of finding a particular environment is given by $P(n, x)=\{N ! /[(N-n) ! n !]\}(1-x)^{N-n} x^{n}$, with $N=8$ corresponding to the number of possible sites in the first shell of $\mathrm{Co}$ and $x$ representing the ratio of the $\mathrm{Fe}$ atoms. Here, we used the ratio found by XRF $(x=0.48) . P(n, x)$ can be directly compared to the relative areas of the resonance lines of a spin echo NMR measurement, while the corresponding resonance frequencies are related to the hyperfine fields of the active atom in this particular environment.

Figure 1(a) shows the ${ }^{59} \mathrm{Co}$ NMR spectrum of the $\mathrm{CoFe}$ sample (black dots), the resulting Gaussian lines corresponding to the fitted individual local $\mathrm{CoFe}$ environments (black lines) and the fit using the sum of Gaussian lines (gray line). The widths of the Gaussian lines were constrained to be

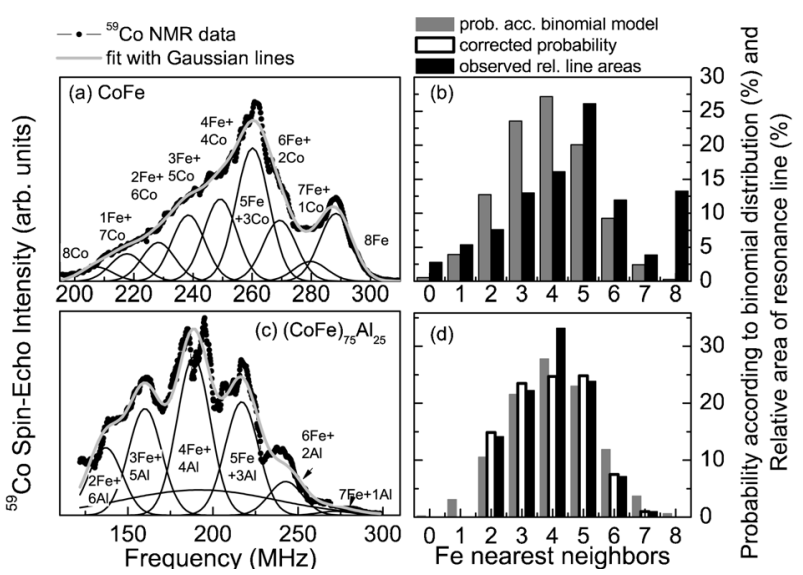

FIG. $1 .{ }^{59} \mathrm{Co}$ NMR spectrum of pure $\mathrm{CoFe}(0$ at. \% $\mathrm{Al})$ (a) the ${ }^{59} \mathrm{Co}$ NMR spectrum of the $\mathrm{CoFe}-\mathrm{Al}$ sample $(25$ at. \% $\mathrm{Al})(\mathrm{c})$ and the corresponding fit with Gaussian lines. The right panels (b) and (d) show a comparison between the random atom model and the relative areas of each resonance line in the fit. 
equal as the width is due to higher order effects that average out across the sample. ${ }^{8,10}$ The fit yields an overall line width of 11.0 $\pm 0.5 \mathrm{MHz}$. All frequencies for certain local environments are found to agree well with those observed by Jay et al. ${ }^{10}$ Figure 1(b) shows a comparison between the relative areas of the Gaussian lines and the probability according to the binomial model. For a 1:1 stoichiometry, this model predicts a preferred environment of $4 \mathrm{Fe}+4 \mathrm{Co}$ atoms that correspond to the peak at $249 \mathrm{MHz}$. By contrast, the main resonance line is found at $260 \mathrm{MHz}(5 \mathrm{Fe}+3 \mathrm{Co}$ local neighbors). Moreover, the line at $288 \mathrm{MHz}$ (eight Fe neighbors) is much more prominent than expected assuming a perfect random distribution of $\mathrm{Co}$ and $\mathrm{Fe}$ and hints at preferential ordering. The corresponding atomic environment for this line consists of eight $\mathrm{Fe}$ atoms in the first shell and, thus, corresponds to an ordered $B 2$ type lattice. The enhancement of this line was also observed by Jay et al. ${ }^{10}$ Thus, there seems to be a mixture between a random distribution and a locally ordered environment, which is perhaps the result of the CoFe layer being sputtered and subsequently vacuum annealed for $5 \mathrm{~h}$ at $518 \mathrm{~K}$, allowing some of the atoms to arrange themselves in the observed preferred environment (see supplementary material for details about the NMR spectrum of the additionally annealed sample). ${ }^{9}$ Thus, the as-prepared CoFe alloy prefers the randomly ordered bcc structure and gradually orders in the $B 2$ lattice upon additional annealing. These spectra give a good indication of what a CoFe alloy would look like in a CoFe-Al sample.

In order to follow the local changes upon addition of $\mathrm{Al}$ to $\mathrm{CoFe}$, we measured several samples with different $\mathrm{CoFe}-\mathrm{Al}$ compositions. Figure $1(\mathrm{c})$ shows the ${ }^{59} \mathrm{Co} \mathrm{NMR}$ spectrum of a sample with $25 \%$ of $\mathrm{Al}$ in more detail. For this sample, the XRF analysis determined a composition of 38.52 at. $\% \mathrm{Co}, 36.27$ at. $\% \mathrm{Fe}$, and 25.21 at. $\% \mathrm{Al}$. This is also the composition that was found to exhibit the highest magnetoresistance within the $\mathrm{Al}$ series. ${ }^{2}$ Assuming that $\mathrm{Co}, \mathrm{Fe}$, and $\mathrm{Al}$ form an $A 2$ bcc alloy, in which all atoms are randomly distributed over the lattice, this would lead to one broad line located around $190 \mathrm{MHz}$ without pronounced peaks ${ }^{8,11}$ as the hyperfine fields and the resonance lines of the local environments with different numbers of $\mathrm{Co}, \mathrm{Fe}$, and $\mathrm{Al}$ neighbors would overlap. Instead, one clearly observes six distinct lines with a substructure and a broad "background" line. Note that due to technical limitations, only measurements above 100 $\mathrm{MHz}$ are possible. The clear observation of distinct main lines points to a higher degree of order than the completely randomly ordered $A 2$ type structure.

For a discussion about possible structure types for ternary alloys and their related NMR spectra see Ref. 9.

The six resonance lines observed in Fig. 1(c) and the main resonance line found at $190 \mathrm{MHz}$ are in good agreement with the main resonance found for a $B 2$ type ordered $\mathrm{Co}_{2} \mathrm{FeAl}$ Heusler compound. ${ }^{8,11,12}$ This peak at $190 \mathrm{MHz}$ corresponds to local environments with $4 \mathrm{Fe}+4 \mathrm{Al}$ neighbors. Higher frequency peaks correspond to Fe rich environments while lower frequency peaks correspond to $\mathrm{Al}$ rich environments. $^{8,11,12}$ The mean spacing between adjacent resonance lines is similar to those found for a $B 2$ ordered $\mathrm{Co}_{2} \mathrm{FeAl} \mathrm{Heusler} \mathrm{compound}(27 \mathrm{MHz}$ ). Seemingly, the NMR spectrum of the ternary $\mathrm{CoFe}-\mathrm{Al}$ alloy exhibits the characteristics of the corresponding $B 2$ ordered Heusler compound. In particular, the best fit was obtained by assuming six reso- nance lines representing a $B 2$ type structure in addition to a broad resonance line. This broad line represents $A 2$ type contributions of a completely disordered $\mathrm{CoFe}-\mathrm{Al}$ alloy, which is similar to the one found in a $\mathrm{Co}_{2} \mathrm{FeAl}$ Heusler sample with a mixture of $A 2$ and $B 2$ contributions. ${ }^{8}$ Moreover, the line at $190 \mathrm{MHz}$ is more prominent than expected for a pure $B 2$ type ordering (see Ref. 8) that points to a preferential enhancement of the $4 \mathrm{Fe}+4 \mathrm{Al}$ environment. In line with the considerations above and Ref. 8, the considerations above, this enhancement points to the formation of $L 2_{1}$ environments on a local scale. It may be concluded that the spectrum of the $\mathrm{CoFe}-\mathrm{Al}$ alloy consists of a mixture of the $A 2, B 2$, and $L 2{ }_{1}$ Heusler type structure. To confirm and quantify, we compared the observed areas of the Gaussian lines (black bars) and the probability according to the binomial model in two ways excluding (gray) and including (white) $A 2$ and in particular $L 2_{1}$ contributions as described in Ref. 8, (Fig. 1(d)). It clearly indicates that the NMR spectrum of the $\mathrm{CoFe}-\mathrm{Al}$ alloy closely follows the binomial distribution expected for a $B 2$ type ordered $\mathrm{Co}_{2} \mathrm{FeAl}$ Heusler compound with about $19 \%$ of $A 2$ type contributions and about $3 \%$ of $L 2_{1}$ contributions. The additional substructure of the main lines originates in higher shell effects. ${ }^{8}$

Figure 2 shows the ${ }^{59} \mathrm{Co}$ NMR spectra for $(\mathrm{CoFe})_{1-x} \mathrm{Al}_{x}$ samples with different $\mathrm{Al}$ contents. The same fitting procedures as described above were applied to all spectra except for the $19 \% \mathrm{Al}$ sample where the line at $243 \mathrm{MHz}$ has a much smaller line width of $7 \mathrm{MHz}$ (compared to roughly 18 $\mathrm{MHz}$ for all other lines). The $(\mathrm{CoFe})_{1-x} \mathrm{Al}_{x}$ spectra show pronounced peaks that can be attributed to different local environments for the ${ }^{59} \mathrm{Co}$ nuclei. These peaks were fitted by Gaussian lines, leading to an overall fit of the spectrum by the sum of all Gaussian lines (gray line). The measurements show a clear trend of decreasing NMR frequencies for increasing $\mathrm{Al}$ content up to 22 at. \% in agreement with Ref. 12 showing that in $\mathrm{Co}_{2} \mathrm{FeAl}$, the $\mathrm{Fe}$ rich environments are on the high frequency side, while $\mathrm{Al}$ in the first shell decreases the resonance frequency of ${ }^{59} \mathrm{Co}$ nuclei. The black lines in Fig. 2 indicate the positions of the line at $190 \mathrm{MHz}(4 \mathrm{Fe}$ $+4 \mathrm{Al}$ local neighbors) and the line at $280 \mathrm{MHz}(8 \mathrm{Fe}+0 \mathrm{Al}$ neighbors configuration in the $\mathrm{Al}$ free $\mathrm{CoFe}$ alloy). It is clear, however, that the addition of $\mathrm{Al}$ to $\mathrm{CoFe}$ leads to a drastically different local structure than bcc $\mathrm{CoFe}$ and that the contribution of bcc CoFe quickly becomes negligible even for small amounts of Al, as demonstrated by the appearance of the 190 $\mathrm{MHz}$ line (see Fig. 2). The observation of pronounced lines also excludes a random distribution of all atoms in the $\mathrm{CoFe}-\mathrm{Al}$ alloy and can be attributed to different local environments for the ${ }^{59} \mathrm{Co}$ nuclei and therefore to a higher degree of order.

The spectra of the $8 \%$ and $19 \%$ samples are a superposition of the resonance lines originating in the formation of a local Heusler type structure and a randomly ordered $\mathrm{CoFe}$ structure and there is a clear decrease of the $280 \mathrm{MHz}$ line corresponding to only eight Fe neighbors compared to the $0 \%$ sample. This is expected considering that $\mathrm{Al}$ neighbors will enter the higher coordination shells, which will destroy the preferential ordering of the pure Fe coordination compared to the pure CoFe alloy. A clear fingerprint of the resonance lines of a Heusler type ordering is observed for the $22 \%, 25 \%$, and $28 \%$ samples (compare Refs. 8, 11, and 12). Thus, with the addition of $\mathrm{Al}, \mathrm{CoFe}$ has a tendency to form a 


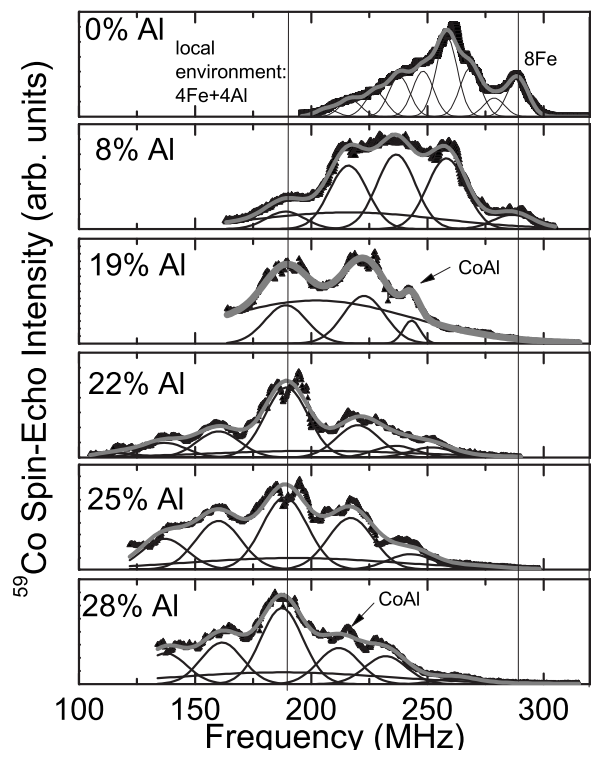

FIG. 2. ${ }^{59} \mathrm{Co} \mathrm{NMR}$ spectra for the $(\mathrm{CoFe})_{1-x} \mathrm{Al}_{x}$ samples.

Heusler compound. In a few of the samples, there is also a noticeable preference for the $L 2_{1}$ ordering with preferred first nearest neighbor shell with $4 \mathrm{Fe}+4 \mathrm{Al}$ atoms. Two spectra (19\% and 28\%) exhibit an additional line in the range of 200-250 MHz with a smaller line width than the line widths attributed to the $\mathrm{CoFe}$ and Heusler resonances (indicated by arrows in Fig. 2), which might originate from a formation of a $\mathrm{Co}-\mathrm{Al}$ alloy. ${ }^{13}$ It is worth noting that formation of a $\mathrm{Fe}-\mathrm{Al}$ alloy would not be detected in the available frequency range, even though it might also be present in the samples. On the other hand, the precipitation of a CoFe alloy is definitely excluded.

The most important question is whether these structural results are correlated with the enhanced GMR. ${ }^{2}$ In order to establish such a relation, we compared the $L 2_{1}$ and $B 2$ type contributions for different samples with the CPP-GMR ratios measured by Maat et al. on $(\mathrm{CoFe})_{1-x} \mathrm{Al}_{x}$ spin-valves (black squares in Fig. 3). The dotted line indicates the sample with $0 \% \mathrm{Al}$ (no Heusler contribution) and hence the CPP-GMR ratio of the pure CoFe alloy. According to Fig. 3, the CPPGMR ratio and the formation of a highly spin-polarized Heusler compound seemingly follow a similar trend upon $\mathrm{Al}$ addition. In particular, the highest GMR ratios are obtained for those $\mathrm{Al}$ contents that also show a high $B 2$ and $L 2_{1}$ type contribution (samples with $22 \%$ and $25 \% \mathrm{Al}$ ). The CPPGMR is lower in the samples with lower Al content $(19 \%$, $8 \%$, and $0 \% \mathrm{Al}$ ) for which the contribution of a Heusler compound is also found to be low by means of NMR. The sample with $28 \% \mathrm{Al}$ shows a comparably high Heusler contribution but a low CPP-GMR ratio. This might be attributed to the observed $\mathrm{Co}-\mathrm{Al}$ separation, leading to additional spinscattering contributions followed by a decrease of the CPPGMR ratio. In particular, it should be noted here that the CPP-GMR will also depend on such parameters the thickness of the layers, spin-diffusion length, interfacial scattering, and growth imperfections such as atomic interdiffusion across interfaces.

The clear observation of the characteristics of both $B 2$ and $L 2_{1}$ contributions to the spectrum confirm the local formation of a Heusler compound upon addition of $\mathrm{Al} . \mathrm{Co}_{2} \mathrm{FeAl}$ in the $B 2$ type structure is predicted to conserve the high spin

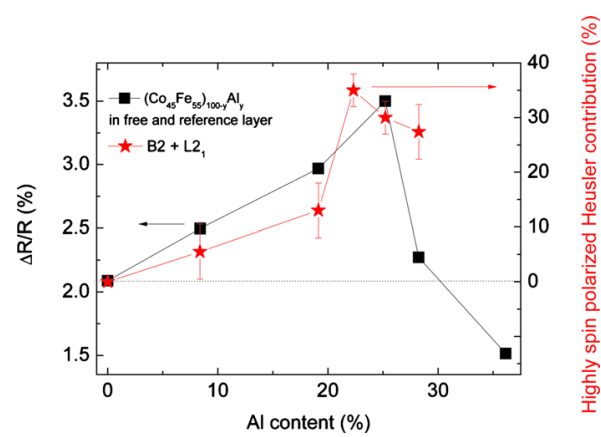

FIG. 3. (Color online) Comparison between the CPP-GMR properties ( Ref. 2) and the contribution of highly spin-polarized Heusler compound both as a function of the $\mathrm{Al}$ content of the $(\mathrm{CoFe})_{1-x} \mathrm{Al}_{x}$ samples.

polarization ${ }^{14-16}$ assumed for $\mathrm{Co}_{2} \mathrm{FeAl}$ in the $L 2_{1}$ type structure and consequently, the bulk spin-scattering asymmetry in the CPP-GMR spin-valves.

In summary, we systematically studied the changes in local environments upon addition of $\mathrm{Al}$ to the $\mathrm{CoFe}$ alloy in CPP-GMR multilayers by means of NMR. We have established that a $\mathrm{Co}_{2} \mathrm{FeAl}$ Heusler type structure is formed on a local scale. The formation of a high spin polarization upon $B 2$ and $L 2_{1}$ type ordering is seemingly related to the observed improvement of the magnetotransport properties. For further performance increases with $\mathrm{CoFe}-\mathrm{Al}$, the chemical order needs to be improved further toward $L 2_{1}$ and $B 2$ ordering, which however may require higher-temperature annealing. Practical limits on the annealing of recording head wafers $\left(\approx 300{ }^{\circ} \mathrm{C}\right)$ create a challenge in implementing such improvements without other negative effects.

S.W. acknowledges support from the Deutsche Forschungsgemeinschaft DFG in Project No. WU595/3-1.

${ }^{1}$ A. Jogo, K. Nagasaka, T. Ibusuki, Y. Shimizu, A. Tanaka, and H. Oshima, J. Magn. Magn. Mater. 309, 80 (2007).

${ }^{2}$ S. Maat, M. J. Carey, and J. R. Childress, J. Appl. Phys. 101, 093905 (2007).

${ }^{3}$ R. A. de Groot, F. M. Müller, P. G. van Engen, and K. H. J. Buschow, Phys. Rev. Lett. 50, 2024 (1983).

${ }^{4}$ K. Kodama, T. Furubayashi, H. Sukegawa, T. M. Nakatani, K. Inomata, and K. Hono, J. Appl. Phys. 105, 07E905 (2009).

${ }^{5}$ K. Yakushiji, K. Saito, S. Mitani, K. Takanashi, Y. K. Takahashi, and K. Hono, Appl. Phys. Lett. 88, 222504 (2006).

${ }^{6}$ K. Nikolaev, P. Kolbo, T. Pokhi, X. Peng, Y. Chen, T. Ambrose, and O. Mryasov, Appl. Phys. Lett. 94, 222501 (2009).

${ }^{7}$ S. Wurmehl, J. T. Kohlhepp, H. J. M. Swagten, B. Koopmans, M. Wojcik, B. Balke, C. G. F. Blum, V. Ksenofontov, G. H. Fecher, and C. Felser, Appl. Phys. Lett. 91, 052506 (2007).

${ }^{8}$ S. Wurmehl, J. T. Kohlhepp, H. J. M. Swagten, and B. Koopmans, J. Phys. D 41, 115007 (2008).

${ }^{9}$ See supplementary material at http://dx.doi.org/10.1063/1.3517490 for experimental details, details of the NMR spectra of $\mathrm{CoFe}$ and additionally annealed $\mathrm{CoFe}$, possible structure types for ternary alloys and their related NMR spectra, and the possible Co-Al separation.

${ }^{10}$ J. P. Jay, M. Wójcik, and P. Panissod, Z. Phys. B: Condens. Matter 101, 471 (1996).

${ }^{11}$ K. Inomata, S. Okamura, A. Miyazaki, M. Kikuchi, N. Tezuka, M Wójcik, and E. Jedryka, J. Phys. D 39, 816 (2006).

${ }^{12}$ K. Inomata, M. Wójcik, E. Jedryka, N. Ikeda, and N. Tezuka, Phys. Rev. B 77, 214425 (2008).

${ }^{13}$ M. Kawakami, Hyperfine Interact. 51, 993 (1989).

${ }^{14}$ S. Wurmehl, G. H. Fecher, K. Kroth, F. Kronast, H. A. Dürr, Y. Takeda, Y. Saitoh, K. Kobayashi, H.-J. Lin, G. Schönhense, and C. Felser, J. Phys. D 39, 803 (2006).

${ }^{15}$ W. Wang, H. Sukegawa, R. Shan, S. Mitani, and K. Inomata, Appl. Phys. Lett. 95, 182502 (2009).

${ }^{16}$ D. Ebke, V. Drewello, M. Schäfers, G. Reiss, and A. Thomas, Appl. Phys. Lett. 95, 232510 (2009). 